\title{
Effectiveness of small-group sessions in enhancing students' generic skills at the Shifa College of Nursing, Islamabad, Pakistan
}

\author{
By \\ Afshan Saleem Daredia \\ Thesis presented in partial fulfillment of the requirements for the degree \\ Masters in Philosophy (MPhil) in Health Sciences Education at the \\ University of Stellenbosch \\ Supervisor: Prof Juanita Bezuidenhout \\ Faculty of Medicine \& Health Sciences \\ Centre for Health Professions Education \\ Co-supervisor: Prof Ben Van Heerden \\ Faculty of Medicine \& Health Sciences \\ Centre for Health Professions Education
}

December 2013 


\section{Declaration}

By submitting this thesis electronically, I declare that the entirety of the work contained therein is my own, original work, that I am the sole author thereof (save to the extent explicitly otherwise stated), that reproduction and publication thereof by Stellenbosch University will not infringe any third party rights and that I have not previously in its entirety or in part submitted it for obtaining any qualification.

December 2013

Copyright (C) 2013 Stellenbosch University

All rights reserved 
Effectiveness of small-group sessions in enhancing students' generic skills at the Shifa College of Nursing, Islamabad, Pakistan

Afshan Saleem Daredia, RN, BScN

Author's Affiliations: Senior Instructor, Mental Health Nursing, Leadership and Management in Nursing, Fundamentals of Nursing, Shifa College of Nursing, Islamabad, Pakistan

Corresponding Author: Afshan Saleem Daredia, Shifa College of Nursing, H-8/4, Pitras Bukhari Road, Islamabad, Pakistan (afshandaredia@gmail.com)

Supervisor: J Bezuidenhout

Co-supervisor: B van Heerden 
Abstract

There is no dearth of evidence of the importance of facilitation for the effectiveness of small-group teaching. However, there is hardly any local literature on the knowledge of untrained facilitators and how they apply this knowledge to develop generic skills in students. Needs identified through this study have provided an insight into the areas requiring formal training that could be useful for developing nursingfaculty development programmes.

Abbreviations: Shifa College of Nursing (SCN), Shifa College of Medicine (SCM), small-group sessions (SGS), small-group facilitators (SGF) 


\section{Introduction}

Small-group learning is an important approach for instruction in health-sciences education. Research has proved that students achieve greater understanding through small-group learning than through any other teaching approach. According to Davis (1), students who learn in small groups retain for longer periods than students who are taught through other instructional modes.

This instructional modality facilitates students' acquisition of generic skills, like problem solving, communication and interpersonal skills (2). These crucial skills are difficult to acquire in large groups, small-group learning having proved to be more effective for this purpose. Small group size provides individual members with the opportunity to participate actively and the change in group dynamics that occurs as a result of an increasing number of participants, and causes the domination of some and continued reservations of shy students (3). According to Gillies, encouraging students to ask questions in small groups is essential if problem solving is to be nurtured (4). "Small Group work is a method for generating free communication between the group leader and the members and among all the participants themselves" (5).

The effectiveness of small-group teaching depends largely on careful planning and on the quality of the facilitation, which, in turn, depends largely on the proficiency of the facilitators. The term 'facilitator' (6) is used to refer to individual who fulfils a variety of roles in groups; as leader, mediator, content expert and instructor.

Facilitation is the process that individuals undertake to help identify issues and to encourage problem solving and decision making in the participants, which makes small-group learning more effective (7). These individuals should be acceptable to all, neutral and not be in an authoritative position. Facilitation is ineffective if it is directionless, unproductive, unsatisfying and threatening (8). To avoid these problems, facilitators should have an understanding of how groups work and how small-group techniques improve learning and the generic skills of students. 
According to the cognitivist-orientation theory (9), learners develop critical thinking by sharing their views and experiences. The role of facilitators is important because they provide learners with the opportunity to question and work within teams, which promotes cognitive processing. In order to be effective, facilitators need to have understanding of the topic, to be involved in all the stages of planning, to understand the purpose of the small group and importantly, to have knowledge of facilitation techniques (10).

According to Dario's social-learning framework theory (9), "the locus of learning in the social model is on the interaction between the person, the learning environment and the desired behaviour". Based on this theory, teachers are responsible for guiding students' behaviour and for modelling new roles, while providing them with the opportunity to practise these. This highlights the fact that, only if facilitators are trained to conduct small-group sessions (SGS) will students benefit and their learning be enhanced.

At Shifa College of Nursing (SCN), students are provided with various opportunities to interact and learn in SGS, particularly when they are on clinical rotations. These groups comprise six to twelve members facilitated by a faculty member. During each clinical rotation, students discuss their patients' problems, they are encouraged to participate actively in their groups and they are supported to improve their generic skills.

The facilitators at the SCN do not undergo any structured training for facilitation. This led us to believe that a needs-assessment exercise would help to understand the current proficiency of the small-group facilitators (SGF) and identify the need for formal intervention in order to address any deficiencies.

The primary aim of this study was to determine whether the facilitators of SGS have the knowledge or expertise required to develop learners' generic skills and to evaluate their application of this knowledge.

The objectives were to determine:

- The facilitation skills of facilitators through the observation of their SGS.

- The students' perceptions of skills of the facilitators in developing generic skills. 
- To identify the general behavior and awareness of the facilitators regarding skills required for developing generic skills in the learners.

\section{Methods}

This mixed-method study design was approved by the Institutional Review Board of the Shifa College of Medicine (SCM), the SCN and the Human Research Ethics Committee of Stellenbosch University. Written informed consent was obtained from the students and facilitators prior to the study. Information about the study, its purpose and potential benefits were explained and confidentiality was guaranteed.

The sample consisted of 13 out of 16 SGF from the BSc Nursing programme who consented to participate. Four of these were senior instructors, six were instructors and three were assistant instructors. A faculty member from the SCM was identified by the dean to observe all the participating facilitators in action.

Each planned SGS was observed by the faculty observer and evaluated using an observation check-list (Appendix 1). The students also evaluated each SGS using the observation check-list. One small group session of each facilitator was observed by two observers; the faculty observer and the student. Self assessment questionnaire was developed, piloted and validated by the Department of Community Health Sciences of the Shifa College of Medicine in the beginning of 2009. Researcher has adopted this questionnaire at the end of 2009 when the research methodology module was running. Before adapting the questionnaire few of the changes, according to the SCN, were made and again piloted at SCM before adapting for study. Changes were made after piloting and the tool was revalidated.

This validated instrument comprised 17 items. The facilitator evaluated herself or himself using a selfassessment questionnaire (Appendix 2), which was a 15-item instrument developed and piloted in the SCM.

At the end of each SGS, the author explained details of the study to students and obtained their written consent. Ambiguous terms in the check-list were also clarified. The average time of each SGS was 45 
minutes. Altogether there were 119 students who completed the questionnaire and per group there were 8 to 10 students.

All duly completed check-lists were collected for data compilation and analysis.

Three sources were therefore used for data collection:

- An observation check-list completed by the faculty observer

- An observation check-list completed by the students attending the SGS

- A self-assessment questionnaire completed by the participating facilitators

\section{Results}

The quantitative data were analysed using SPSS -15. Descriptive statistics were then performed. The qualitative data were cleaned and common themes were identified.

Observations of the facilitator by the students and faculty observer

From Table 1, it can be seen that, according to the students, $92.4 \%$ of the facilitators focused on the seating arrangements, whereas the faculty observer thought that $100 \%$ of the facilitators made sure that their students were sitting in a circle or semi-circle.

The faculty observer identified around $>85 \%$ of the facilitators encouraging thinking inquiry, critical reasoning and a safe environment, and accommodating six to twelve students in a group. The students, however, thought that, although $89.1 \%$ encouraged thinking and had a conducive environment, $92.4 \%$ had appropriate-sized groups.

The faculty observer identified $67 \%$ of facilitators demonstrating sensitivity 4 towards the students, and refocusing 8 the groups when discussion was digressing. The students, however, thought that most of the facilitators demonstrated these qualities. This difference was found to be significant ( $P$ value 0.000$)$. 
One more significant difference was found ( $P$ value 0.000$)$ where the faculty observer identified $33 \%$ of facilitators encouraging participation 7 of all the members and presenting adequate resource material15 in small group.

Another significant difference was found where the faculty observer identified $20 \%$ participated in group discussion 6 , whereas, students thought that $82.4 \%$ students participated ( $P$ value 0.000 ).

According to both students and the faculty observer, only $7.5 \%$ did not provide adequate feedback 13 when appropriate.

$40 \%$, according to the faculty observer, and around $86 \%$, as identified by the students, of the facilitators encouraged quiet 9 students to participate. This difference in the two responses was also significant $(P$ value 0.000 )

Another significant difference was seen in the faculty observer noting $53 \%$ of the facilitators encouraging the students to assume leadership responsibility11 within the group, whereas the students thought that $86 \%$ were successful in this context ( $P$ value 0.000$)$. All difference between the faculty observer and the students perceptions maybe due to the difference in expertise and experiences of the two. The faculty observer had observed and conducted many small groups of similar students and was well versed with the skills that needed to be displayed by the facilitators. The students, on the other hand, were enthusiastic young adults with none or very limited exposure to properly conducted small groups hence responded positively to most of the facilitation.

The overall rating of effectiveness 16 by the students was moderate for $19.3 \%$ of the facilitators, high for $26.1 \%$ of the facilitators and very high for $52.1 \%$ of the facilitators. In contrast, the faculty observer thought that $53.3 \%$ of the facilitators were at a high level of effectiveness and $46.7 \%$ of the facilitators were at a very high level of effectiveness. Regarding overall value of the session 17 , the students thought that $18.5 \%$ was moderate $26.1 \%$ was high and $53.3 \%$ was very high. Whereas according to faculty observer $60 \%$ value the session was at high level and $40 \%$ was at very high level. 
Self-assessment questionnaire

\section{Quantitative data for the knowledge and perceptions of the facilitators}

According to Table 2, all the facilitators had previously conducted SGS. More than $50 \%$ of the facilitators had already conducted SGS more than 15 times. Most of the facilitators $(85 \%)$ were in a habit of planning SGS in advance. Forty per cent of the facilitators found it difficult to select a learning strategy. Nearly $15 \%$ of the facilitators faced difficulty in providing pre-session reading material, while around $8 \%$ had difficulty in communicating the intended outcome before the session and $15 \%$ of the facilitators mentioned "Other" difficulties but failed to identify them.

Forty percent of the facilitators said that they did not pre-plan objectives for developing generic skills in students through SGS and faced problems in facilitating SGS but $60 \%$ did not respond to this item. Fifteen percent of the facilitators faced time-management issues and around $8 \%$ found it difficult to engage the students. More than $50 \%$ of the facilitators did not respond to how they identified issues but around $8 \%$ said that they identified issues through feedback, around $15 \%$ through formative evaluation and $23 \%$ through self-reflection and observation. Furthermore, around $70 \%$ of the facilitators demonstrated awareness of the importance of how and why-questions in developing critical thinking. More than $90 \%$ of the facilitators preferred training workshops to presentations.

A few of the questions of the self-assessment questionnaire were open-ended and required explanations from the facilitators. A content analysis of their responses was carried out and the identified themes are presented in Table 3.

\section{Qualitative data for the knowledge and perceptions of the facilitators}

Note: The responses of the participants have been included in this paper in their original words; however, a few improvements in grammar were made without changing the gist of the responses. 


\section{Discussion}

The importance of small-group discussions as a learning strategy has been established time and again; the nature of interaction in small groups provides an opportunity for students to become actively involved in the process of learning. Facilitators, however, need to apply strategies like effective questioning, active listening and the reinforcement of individual contributions to promote individual involvement, active participation and critical thinking $(11,12)$. Effective facilitators provide a non-threatening environment where the students have no fear of humiliation, where their communication improves and learn the principles of therapeutic communication. The responsibility of interacting with and listening to the whole group and not allowing domination by a selected group of individuals lies with the facilitators. The effectiveness of small groups is therefore determined by the quality of facilitation and the expertise of the facilitators.

According to our findings, almost all the faculty members had received the chance to conduct SGS either at the SCN or at other organisations where the same strategy for teaching was used. The SGF of the SCN undergo no any formal training in facilitation. The needs-assessment exercise therefore helped to identify areas that require formal training.

Majority of our samples were successful in providing the relevant ambience for student learning. Evidence shows that the seating arrangements in the classrooms should be such that they facilitate eye contact and the observation of non-verbal behaviours, thus facilitating discussion (13).

Although there was no significant difference in the students and the faculty observer's perceptions of the appropriateness of the logistics, a few observations has shared about the group layout was inappropriate. The reason for this may be that the respondents had attended better sessions or had read literature on effective logistics.

Critical facilitation skills, like encouraging the participation of shy students, keeping discussions focused and involving all the group members, were found to be deficient by the faculty observer. In general, the observations of the faculty and students' observer about the facilitators' skills were similar. The students 
were found to be active participants in small groups and the majority of the facilitators encouraged the students to participate.

A few of the students thought that the facilitators did not explain the tasks to them, possibly because they had different perceptions of "explanation". Most of the students of the SCN came from a traditional system of education and were therefore more teacher-dependent, expecting notes and lectures from the teachers. Additionally, they were not receptive to being asked to perform tasks and to prepare for the sessions in advance. It would have been interesting to see if this was the same group that had different ideas about the classroom setting as well.

Effective facilitation advocates people-centeredness by ensuring collaboration among participants. This empowers individuals and strengthens their ability to plan, reflect and learn from each other (7).

Our needs-assessment exercise showed that a good number of facilitators did not plan their sessions because of workload and poor management skills. This important prerequisite - that of planning - has been reinforced by Steinert (12), who believes that preparation for small-group teaching, is the key to successful learning. It is suggested that preparation for sessions needs to be based on what the facilitators want their students to learn, how they want them to learn it and how they confirm that the learning has occurred. Most of the facilitators had difficulty in planning their SGS. Even those facilitators who thought that they had planned their sessions ended up identifying issues in their planning of the sessions. Nearly half of the facilitators made no conscious effort to plan or use strategies to promote generic skills in their learners.

Most of the facilitators reflected and realised that they needed to improve their facilitation skills. Although they did demonstrate awareness-questions that explore students' learning, that is "how" and "why" questions, and that encourage critical thinking skills, they did not demonstrate their use in their sessions. Though they realised the importance of such exploration, but did not modify their facilitation to apply this knowledge. 
The facilitators shared that SGF should be ethical, professional, friendly yet respectful, skilled in questioning and in providing feedback and content experts. They realised that it is very important in the local context to encourage every student to participate, as the students come from diverse backgrounds and languages. It was observed in the SCN that learners with urban educational opportunities are more confident and actively participate in discussions and that students from a rural educational background are shy and requires greater attention and encouragement from facilitators to enhance their communication skills. Students, especially those who are timid and introvert are nervous about speaking in groups and facilitators therefore need to provide an environment in which they do not feel threatened to speak up (12). This, as discussed earlier, is a deficiency in untrained facilitators.

The majority of the facilitators felt that one of their strengths lay in involving and accommodating each and every student in the discussions; this, however, was not corroborated by the faculty observer or the students. The facilitators thought that their weakness lay in their preparation for the SGS, which was not thorough because of time constraints and work overload. If the facilitators were equipped with managerial skills, however, they would be able to manage their time more effectively. One of the participants said that he became so involved in the discussion that he started providing the students with answers. This is a universally identified issue - that of a tutor giving a lecture rather than conducting a dialogue or talking too much and discouraging student participation (12). The students' and observer's findings of most of the skills of the facilitators were similar but it is clear that, where the students thought that the facilitators were good in certain skills (like encouraging participation, involving students, showing respect, encouraging quiet students and providing resource material), the faculty observer did not agree. The reason for this may be that these technical and higher skills were or could not be judged by the students, who have no idea about the dynamics of facilitation.

\section{Conclusion}

Our results show that formal training of facilitators is required in planning through adequate and appropriate resources, guidance in how to keep discussions focused and ensuring participation of every member of the group. The facilitators require formal guidance in how to demonstrate sensitivity towards 
the students and how to apply their knowledge of facilitation of small groups to real-life teaching. Regular and sequential workshops focusing on developing these skills are required. Appropriate methodology should be used to ensure that these skills are internalised and that inform the practice of facilitators. This study has therefore identified crucial gaps in expertise that require special emphasis; faculty development programmes should be customized in accordance with the results of this study in order to make smallgroup activities achieve a greater level of excellence.

\section{Limitations}

The sample size was small therefore the results could not be generalised. Additionally, only one observer observed the SGS; two or three observers observing the same sessions on repeated occasions would provide more reliable results. Furthermore, conducting focus groups would have added to the richness of data. Moreover data collection at first-year level was challenging because these students were new to the environment and had difficulty understanding the questionnaire and check-list terms.

\section{Acknowledgment}

The author would like to thank Prof Juanita Bezuidenhout, Prof Ben van Heerden and Dr Ayesha Rauf for their support and guidance, Dr Ashraf for observing the SGS and Ms Zahra Ladhani, Dr Mohammad Amin, Dr Mohammad Naseem Ansari, Mr Shomail Sikandar and Mr Faisal Aziz for extending their help wherever it was sought. 


\section{References}

1. Davis BG. Tools for Teaching. San Francisco, CA: Jossey Bass Inc.; 1993.

2. Cannon R, Crosby JR, Hesketh EA. Developing the teaching instinct: Small group learning. Medical Teacher. 2004; 26(1):16-19.

3. Jones RW. Education and training: Learning and teaching in small groups: Characteristics, benefits, problems and approaches. Anesthesia and Intensive Care. 2007; 35(4):587-592.

4. Gillies RM. Promoting thinking, problem-solving and reasoning during small group discussions. Teachers and Teaching: theory and practice. 2011; 17(1):73-89.

5. Walton H. Small group methods in medical teaching. Medical Education. 1997; 31: 459-464.

6. Kolb JA, Song JH. A model of small group facilitator competencies. Inter Science. 2008; 21(2).

7. Schwarz R. The skilled facilitator approach. In: Cannon R, Crosby JR, Hesketh EA. The Skilled Facilitator: A Comprehensive Resource for Consultants, Facilitators, Managers, Trainers and Coaches. 2nd ed. San Francisco, CA: Jossey-Bass; 2002.

8. Jaques D. ABC of learning and teaching in medicine: Teaching small groups. BMJ. 2003:326.

9. Torre DM, Daley BJ, Sebastian JL, et al. Overview of Current Learning Theories for Medical Educators. The American Journal of Medicine. 2006; 119(10): 903-907.

10. Becker A. Facilitating a Small Group Meeting: Principles and Techniques.

11. Edmunds S, Brown G. Effective small group learning. AMEE Guide No. 48. 2010; 32:715-716.

12. Steinert Y. Twelve tips for effective small-group teaching in the health professions. Medical Teacher. 1996; 18(3). 
13. Soliman I. Teaching Small Groups. University of New England; Teaching and Learning Center; 1999.

14. Imel S, Kerka S, et al. More than the Sum of the Parts: Using Small Group Learning in Adult Basic and Literacy Education. Ohio State University, $\mathrm{OH}$ : Center for Education and Training for Employment; 1994.

15. Cantillon P. ABC of Learning and Teaching in Medicine. BMJ; 2003.437-440.

16. Boldly G. Practical Guide for Clinical Educators; Teaching small groups. Monash University: Faculty of Medicine, Nursing and Health Sciences; 2009. 